\title{
FORMATION OF THE CULTURE OF BRAIN WORK OF PRIMARY SCHOOLCHILDREN IN THE CONTEXT OF INCLUSIVE ENVIRONMENT
}

\author{
Anatoliy Podufalov \\ Postgraduate Student, Vinnytsia Mykhailo Kotsiubynskyi State Pedagogical University, Ukraine \\ e-mail: 444podufalov@ukr.net, orcid.org/0000-0001-7081-0197
}

\section{Summary}

The culture of brain work is a psychological and pedagogical phenomenon that testifies to the level of development of intellectual, cognitive, research and organizational qualities of the learner. These components are identical in both pupils with typical and atypical development (with visual, hearing, speech, musculoskeletal disorders), and due to the development of activity, independence, creativity, motivation of students, these components show a positive dynamics in the whole sample of pupils. The experimental work studied the ability to analyze and synthesize and the nature of verbal creativity of pupils (cognitive component), motivation to learn (motivational component), emotional state of children during classes (emotional-volitional component), independence and activity in educational activities (activity component). A system of exercises that stimulate the development of the culture of brain work and encourages pupils with atypical development to participate in various types of educational activities pair and group work, projects, didactic games, joint collective creativity has been developed. Pedagogical conditions which promote development of the culture of brain work of primary schoolchildren with special educational needs and with standard development are defined: the teacher chooses didactic methods, techniques and tools which will stimulate verbal creativity and group communication; creating a situation of success for each student in an inclusive class by encouraging originality and independence; observance of the principles of pedagogical optimism, faith in the strength of the child, accessibility and emotionality of learning material.

Keywords: learning motivation, creativity, metaphor, cooperative learning, group communication, independence of pupils, students with atypical development, learning strategies, idiomatic expressions, figurative meaning of the word.

\section{DOI: https://doi.org/10.23856/3864}

\section{Introduction}

The inclusion of children with special educational needs in educational process of the modern school is one of the priorities for the development of educational systems in many countries around the world today. The impact of social interaction on learning outcomes in inclusive classrooms, both for children with special needs and for their peers with typical development, has become the subject of considerable research in recent years. Along with this, the practice of introducing various technologies into the inclusive educational process is spreading, since the "society of skills and competencies" requires a transition to the paradigm of knowledge acquisition (learning through activities), development of student's and teacher's intellectual potential, development of new ways to spread information and learn new material (learning through discovery), broad networking (learning in collaboration), the introduction of methods of psychological influence on the student audience for both purely didactic and purely developmental and educational purposes (gamification, transformation games, socio-psychological trainings aimed 
at the development of soft skills, as well as inclinations and abilities of the child). The variety of ways, tools, methods, techniques and forms of learning that the school offers today to different categories of students, aims to create conditions for intellectual development of each student, children's and adolescents' mastering skills to independently acquire knowledge, process, analyze and interpret large flows of information from various sources. The formation of such skills requires, in its turn, mastering culture of brain work by schoolchildren. The latter is a psychological and pedagogical phenomenon that indicates the level of development of intellectual, cognitive, research and organizational qualities of the learner.

In view of the above, one of the issues that needs to be urgently solved is: is it possible to form the culture of brain work of primary schoolchildren with both typical and atypical development in the context of inclusive educational practices?

According to the analysis of pedagogical periodicals, for the most part this area of work in inclusive education is not given paramount importance, meanwhile due to the involvement of a special child in the process of educating the culture of brain work it is possible to enter the zone of its immediate development (L. Vyhotskyi), to stimulate cognitive interests, motivation for different activities, to communicate with peers, etc. (T. Loreman et al., 2008).

The purpose of our study is to determine the psychological and pedagogical conditions for the formation of the foundations of the culture of brain work of primary schoolchildren in inclusive classes.

\section{The culture of brain work as an object of psychological and pedagogical analysis}

The concept of brain work in pedagogical science traditionally means perception, processing, synthesis, analysis of information by mobilizing resources of memory and attention. However, the strain of mental energy, intense mental work reduces a person's activity and leads to pathological functioning of attention and memory. Therefore, the culture of brain work can be a kind of guarantor from various negative consequences of the concentration of mental effort, which is especially important for children with atypical development, visual, hearing, speech disorders, who learn in terms of educational integration. The basis for the formation of the culture of brain work is cognitive activity of a pupil, which, in its turn, stimulates the development of cognitive motives and interests, intellectual abilities, values-based attitude to knowledge, mastering rational ways and methods of perception of learning material, independent use of information (A. Zubra, 2002).

Scientific understanding of the culture of brain work is concentrated around the concepts:

- the ability to learn, i.e. to know the system of rational techniques that characterize the style of mental activity;

- the internal mental structure of the individual, which ensures the readiness of pupils to learn the material, forms cognitive motives, interests, worldview and spiritual world of the individual (E. Kabanova-Meller, 1968). Based on the generalization of different views of scholars on the essence of the culture of brain work, we concluded that this concept should be presented as a system of knowledge, skills and abilities of brain work, rapid and accurate acquisition of new knowledge, their active processing and proper reproduction in accordance with mental norms and rules of mental activities. The culture of brain work includes a positive attitude of the schoolchild to the content and process of learning, to the effective possession of knowledge and methods of activity, mobilization of willpower aimed at achieving educational goal - and all this requires personal activity, development of his/ her motivational sphere. 
To build a strategy and determine psychological and pedagogical conditions for the development of the culture of brain work of a primary school child, it is necessary to analyze the components that are part of the structure of this psychological phenomenon. The approaches of domestic researchers to the definition of the essence and content of the concept of "the culture of brain work" allow us to identify such components of its structure as motivational, cognitive, emotional and activity.

\section{Diagnosis of the culture of brain work of primary schoolchildren}

Speaking of developing the culture of brain work of primary schoolchildren, especially children with atypical development in the context of educational inclusion, we mean the comprehensive development of all universal learning activities that are included in this concept, allow to build micro- and macro-strategies of cognition as well as personal qualities, attitude to mental activity, general educational skills and abilities, rational methods and ways of work. Summarizing the above views on the structural components of the culture of brain work of primary school children, we distinguish cognitive, motivational, emotional-volitional and activity components in the structure of this phenomenon. The logic of our reasoning and the choice of methods and tools for diagnosing the formation of components of the culture of brain work in primary schoolchildren is due to the basic provisions of the system-activity approach. In the context of this approach, psychological functions and abilities of the individual are the result of the transformation of external subject activity into internal mental activity, and the leading principle in learning is the principle of conscious activity, the implementation of which involves the development of cognitive abilities of the child through independent work on new material and gaining practical experience (O. Leontiev, 1975; H. Shchedrovytskyi, 1996).

Therefore, to study the process of forming the foundations of the culture of brain work of primary schoolchildren in inclusive classes and tracking the dynamics of changes in the development of all pupils, we chose to study the ability to analyze and synthesize and verbal creativity of students (cognitive component), motivation to learn (motivational component), detection of emotional state during the lesson (emotional-volitional component), independence and activity in educational activities (activity component).

\section{Research methodology, sample characteristics}

Before the start of the experimental work, we conducted a diagnostic assessment of the current level of the formation of the foundations of the culture of brain work (according to the selected components) of primary schoolchildren, where the inclusive educational process is implemented. The experiment involved 37 students from different grades, 2nd and 3rd grades, age - 9-10 years, including 9 children with special needs - speech disorders, musculoskeletal disorders, visual and hearing impairments, children with autism did not participate in the study (due to parental disagreement). At the beginning of our experiment, we suggested that the culture of brain work of pupils in an inclusive learning environment should be formed in all pupils without exception - both with typical and atypical development. The structural components of this personal education are identical in all categories of students. Some methods and techniques of traditional learning, aimed at forming the cognitive and activity components of the culture of brain work, can cause difficulties for students with atypical development. Given this, we selected such didactic methods and techniques in the experimental work that allowed to involve all students without exception and positively influence the development of thinking, speech, 
psyche of the child (cooperative learning, verbal and nonverbal creativity, didactic games). Before the start of training under experimental pedagogical conditions, we conducted an ascertaining assessment of the current level of formation of components of the culture of brain work of pupils with both typical and atypical development (stage 1), at the end of the experiment, 10 months later, we conducted second assessment, control (stage 2), to identify progress in the development of the culture of brain work of pupils. The first and second diagnostic assessments were performed according to the same methods of psychodiagnostics.

We used the following techniques:

A) Method of assessing a fairy tale composed by a child to determine the ability to analyze and synthesize and verbal creativity of pupils (O.M. Diachenko and others, 1996).

B) Test by A. Lutoshkin "Climate" to identify the emotional state of children.

C) Test "Let's dream a little" (own interpretation of R. Nemov's technique) for creative thinking to determine independence and activity in educational activities.

D) Diagnosis of learning motivation according to the technique "Why do I study?"

\section{The results of diagnostic assessments at different stages of the experiment}

We will briefly describe the data obtained as a result of psychodiagnostics on all components of the personal phenomenon "culture of brain work of a primary schoolchild" in pupils of inclusive classes.

A) Method of assessing a fairy tale composed by a child.

The child is asked to compose a fairy tale, which is evaluated on a five-point scale, taking into account indicators of productivity, variability and originality: 0 points - refusal of the task or retelling a familiar fairy tale; 1 point - retelling of a familiar fairy tale, but with the introduction of new elements; 2 points - significant elements of novelty are introduced into a famous fairy tale; 3 points - elements of novelty are introduced into the famous fairy tale and details are added; 4 points - completely independently made up, but presented schematically fairy tale; 5 points - a detailed presentation of a self-composed fairy tale.

During the experimental work, almost all students composed their own fairy tales, which was in line with the task of programs in the Ukrainian language and the discipline "I explore the world" - these are tales about nature, animals, friends.

Here are fragments of fairy tales composed by children with visual and hearing impairments on their own, without the help of the teacher's assistants.

"A little hedgehog wanted to become strong and brave. Because all the time he was afraid of something and curled up in a ball. Everyone saw only his needles, and no one saw his eyes and did not know that he could laugh" (Artem, 9 years old).

"The mouse knew that she had to stock up on food for the winter, so she came to a man and asked him to give her some grain, but the man was wicked, so he didn't give anything. And she gnawed his sacks of grain. We must share with those who are in a worse state than you" (Natalka, 9 years old).

"One night I turned into Superman and rescued a woman and a child from robbers, then helped to get a cat sitting on a tall tree crying, and then rescued an eagle that had a broken wing and could not reach the nest. In the morning it seemed to me that I had a dream, but an eagle feather was lying on the windowsill in my room and my mother wondered where it came from" (Vadim, 10 years old).

Analysis of the fairy tales of all pupils who participated in the experiment allowed us to draw the following conclusions: almost all children came up with their own fairy tales, no 
one gave up this task, no one retold famous works, a third of respondents used elements (plots and characters) of famous fairy tales, but with their own interpretations, half of the children presented the story schematically (mostly all children with special educational needs, which we explain primarily by emotional stress and fatigue when performing this task), the rest of the participants gave detailed stories with beginnings and endings.

We summarized the results in Table 1 . We presented the percentage of results separately by the lines "Children with special educational needs" and "All pupils of inclusive classes" in order to see which part of children had the ability to analyze and synthesize, were active in cognition and sought to self-realization in learning (4 and 5 points according to the analyzed method) in their categories.

Assessment of a fairy tale composed by a child

\begin{tabular}{|c|c|c|c|c|c|c|c|}
\hline & &  & 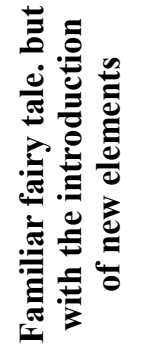 & 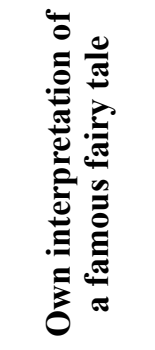 & 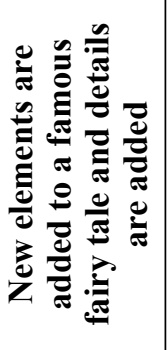 & 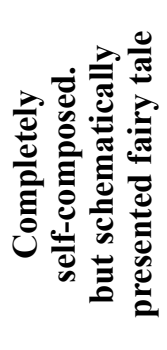 & 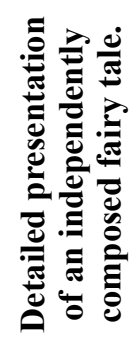 \\
\hline $\begin{array}{c}\text { Children } \\
\text { with special }\end{array}$ & $\begin{array}{c}\text { Stage } \\
1 *\end{array}$ & - & $\begin{array}{c}2 \text { people } \\
(22 \%)\end{array}$ & $\begin{array}{c}4 \text { people } \\
(44 \%)\end{array}$ & $\begin{array}{c}1 \text { person } \\
(11 \%)\end{array}$ & $\begin{array}{c}1 \text { person } \\
(11 \%)\end{array}$ & $\begin{array}{c}1 \text { person } \\
(11 \%)\end{array}$ \\
\hline (9 people) & $\begin{array}{c}\text { Stage } \\
2 * *\end{array}$ & - & $\begin{array}{c}1 \text { person } \\
(11 \%)\end{array}$ & $\begin{array}{l}1 \text { person } \\
(11 \%)\end{array}$ & $\begin{array}{c}2 \text { people } \\
(22 \%)\end{array}$ & $\begin{array}{c}3 \text { people } \\
(33 \%)\end{array}$ & $\begin{array}{c}2 \text { people } \\
(22 \%)\end{array}$ \\
\hline $\begin{array}{l}\text { All pupils } \\
\text { participat- }\end{array}$ & $\begin{array}{c}\text { Stage } \\
1 *\end{array}$ & $\begin{array}{c}2 \text { people } \\
(5 \%)\end{array}$ & $\begin{array}{l}5 \text { people } \\
(13.5 \%)\end{array}$ & $\begin{array}{c}15 \text { people } \\
(40.5 \%)\end{array}$ & $\begin{array}{l}6 \text { чол. } \\
(16 \%)\end{array}$ & $\begin{array}{l}5 \text { people } \\
(13.5 \%)\end{array}$ & $\begin{array}{c}4 \text { people } \\
(11.5 \%)\end{array}$ \\
\hline $\begin{array}{l}\text { experiment } \\
\text { (37 people) }\end{array}$ & $\begin{array}{l}\text { Stage } \\
2 * *\end{array}$ & - & $\begin{array}{l}4 \text { people } \\
(11.5 \%)\end{array}$ & $\begin{array}{l}4 \text { people } \\
(11.5 \%)\end{array}$ & $\begin{array}{c}8 \text { people } \\
(21 \%)\end{array}$ & $\begin{array}{c}12 \text { people } \\
(32 \%)\end{array}$ & $\begin{array}{c}9 \text { people } \\
(24 \%)\end{array}$ \\
\hline
\end{tabular}

Notes to Table 1-4.

Stage $1^{*}$ - diagnostic results before the beginning of experimental work with pupils of inclusive classes

Stage $2 * *$ - diagnostic results after the completion of experimental work with pupils of inclusive classes

As we can see, at the beginning of the experiment only a few pupils refused to compose fairy tales or retold works familiar to them. At the end of the experiment, there were no such pupils left in the sample, which indicates that the children were interested in experimental learning conditions and the desire for self-realization in educational activities, in particular through verbal creativity. Almost all children with special educational needs showed high activity in educational activities and the desire to self-realize in it, which manifested itself in active verbal creativity and desire to compose original texts.

B) The results of students' of inclusive classes test "Climate" to identify emotional states. 
Identifying emotional states of pupils during classes in inclusive classes



At the beginning of the experimental work, the majority of primary school children chose green, blue and purple, which indicates the ill-preparedness of most pupils to work in a collective creativity, teamwork. The choice of dark colors by children with atypical development testified to the high level of anxiety of most of them, fear of casual communication with classmates in educational activities. Instead, at the end of the experiment, almost all children showed positive dynamics in choosing the color scheme of their mood - most chose bright warm colors, which showed satisfaction with the learning activities, which were based on collective creativity and cooperation.

C) The results of the diagnostics of students in inclusive classes on the test "Let's dream a little" to determine independence and activity in educational activities.

Pupils were offered to use LEGO constructor elements (rectangular bricks in yellow, green, red, and blue) to create a pattern that would include one constructor brick of any color. Each child was given four pieces of the constructor, a sheet of white drawing paper, and colored markers and pencils. The children had to invent any picture, part of which could be one of the bricks of the LEGO constructor - it could be an object, phenomenon or story. It was necessary to place the constructor brick on a blank sheet of paper in any place, and then finish it with pencils or markers to get a complete composition, picture. A picture could be supplemented with new details and ideas to make the picture narrative, attractive, interesting. Upon the completion of the work, the children had to come up with a name for the picture and to write it at the bottom of the sheet. Children had 10 minutes for all tasks.

The results were interpreted according to the following algorithm.

Processing of the results:

a. Levels of development of imagination: level II - the contour of a brick is used as the main detail of the picture, the picture thus is simple, without additions and represents one figure; level II - the contour is used as the main detail, but parts of another figure can be drawn next to it; level III - the contour is used as the main detail, but the picture itself is already a plot, details can be added; level IV - the contour of the geometric figure continues to be the main 
detail, but the picture is a complex plot with the addition of details; level V - the picture is a complex plot in which the contour of a geometric figure is used as one of the details. Points for levels of imagination were accrued as follows: level I - 1 point, level II -2 points, level III 3 points; level IV -4 points, level V -5 points.

b. The degree of flexibility of imagination - the number of pictures for the same plot:

High - imagination is flexible, if all pictures are on different plots, and the picture captures both inner and outer part of the contour (3 points); average - imagination with weak fixation of the image, if two pictures are on the same plot (2 points); low - imagination with a strong fixation of images, if all pictures are on the same plot (1 point).

a. The degree of stereotyping or originality of imagination - content of the pictures.

Typical pictures:

A human (head or torso), a robot, a computer game or cartoon character (such as Steve from Minecraft or Sponge Bob), a window, a geometric shape, a TV-set, a book, house, gift, etc. -2 points. Original pictures - a dinosaur, an aquarium with fish, a turtle, a lighthouse, a sailboat, a spaceship, a box of candies, a medal, a coffee maker were evaluated at 4 points.

The more points a pupil scores on the level and degree of flexibility and stereotypes/ originality of imagination, the more reason we had to talk about the presence of such component of the culture of brain work as independence and creative activity in educational activities. The level of such creative activity was calculated as the arithmetic mean of certain parameters of imagination, with the maximum amount of points that could be scored -4 - corresponded to a high level of activity, 3 points - medium, 2 points - low, 1 point - unsatisfactory level of activity in educational activities.

The results according to the method "Let's dream a little" to determine the creative activity in educational activities at the beginning and at the end of the experiment are presented in table 3 .

Table 3

Determination of creative activity in educational activity of pupils of inclusive classes

\begin{tabular}{|c|c|c|c|c|c|c|c|c|}
\hline \multirow{5}{*}{ Indicators } & \multicolumn{8}{|c|}{ Pupils of inclusive classes (37 people) } \\
\hline & \multicolumn{4}{|c|}{ With standard development } & \multicolumn{4}{|c|}{$\begin{array}{l}\text { With special educational needs, } \\
2 \text { classes ( } 9 \text { people) }\end{array}$} \\
\hline & \multirow{2}{*}{\multicolumn{2}{|c|}{$\begin{array}{c}2 \text { classes } \\
\text { (12 people) } \\
\text { Average point } \\
\end{array}$}} & \multirow{2}{*}{\multicolumn{2}{|c|}{$\begin{array}{c}3 \text { classes } \\
\text { (16 people) } \\
\text { Average point } \\
\end{array}$}} & \multirow{2}{*}{\multicolumn{2}{|c|}{$\begin{array}{c}2 \text { classes } \\
\text { (6 people) } \\
\text { Average point } \\
\end{array}$}} & \multirow{2}{*}{\multicolumn{2}{|c|}{$\begin{array}{c}\text { 3 classes } \\
\text { (3 people) } \\
\text { Average point }\end{array}$}} \\
\hline & & & & & & & & \\
\hline & $\begin{array}{c}\text { Stage } \\
1 *\end{array}$ & $\begin{array}{c}\text { Stage } \\
2 * *\end{array}$ & $\begin{array}{c}\text { Stage } \\
1 *\end{array}$ & $\begin{array}{c}\text { Stage } \\
2 * *\end{array}$ & $\begin{array}{c}\text { Stage } \\
1 *\end{array}$ & $\begin{array}{c}\text { Stage } \\
2 * *\end{array}$ & $\begin{array}{c}\text { Stage } \\
1 *\end{array}$ & $\begin{array}{c}\text { Stage } \\
2 * *\end{array}$ \\
\hline $\begin{array}{l}\text { Level of imagination } \\
\text { development } \\
(\max -5 \text { points })\end{array}$ & 3 & 4,3 & 3 & 4,5 & 2,2 & 3,7 & 3 & 4,3 \\
\hline $\begin{array}{l}\text { Flexibility } \\
\text { (max }-3 \text { points) }\end{array}$ & 1,8 & 2,4 & 1,6 & 2,2 & 1,3 & 1,9 & 1,3 & 2 \\
\hline $\begin{array}{l}\text { Originality } \\
(\max -4 \text { points })\end{array}$ & 2 & 2,9 & 2,3 & 3,2 & 2 & 2,7 & 3,3 & 4 \\
\hline $\begin{array}{l}\text { General creative activ- } \\
\text { ity in educational activ- } \\
\text { ities (arithmetic mean) } \\
\text { ( } \max -4 \text { points) }\end{array}$ & 2,3 & 3,2 & 2,3 & 3,3 & 1,8 & 2,8 & 2,5 & 3,4 \\
\hline
\end{tabular}


As we can see, the average indicators of the level of development of imagination, its flexibility and originality, general creative activity in educational activities in children with typical and atypical development do not actually differ either before or after the experiment, showing similar positive dynamics (in quantitative terms).

b. Diagnostics of learning motivation according to the method "Why do I study?"

The study of learning motivation aimed to determine the dominant motives for learning in pupils of inclusive classes. Children were offered 8 statements on separate cards, which corresponded to 4 internal, cognitive motives, and 4 - to external - social - motives. Each student had the right to choose any 4 cards from the whole set of cards. Cognitive motives: 1 . I study to know everything. 2. I study because I like learning. 3. I study in order to get good grades. 4. I study to be able to solve problems. Social motives: 5 . I study in order to be useful to people. 6. I study so that the teacher is satisfied with my success. 7. I study in order to please my parents with my success.8. I study so that my peers and classmates respect me for my success.

The results obtained using this technique, indicate the ratio of social and cognitive motives of the child's learning, which are determined by their place in the overall hierarchy. If the pupil chooses 2 social and 2 cognitive motives, we conclude about the harmonious balance of motives, which in turn indicates a high level of development of such component of the culture of brain work of primary school children as motivational. If a child chooses 3 social and 1 cognitive motive or all 4 social motives - this indicates a low level of formation of the motivational component of the culture of brain work, as there is a bias towards the expectation of social approval, but not personal development. If a child chooses 3 cognitive and 1 social motive or all 4 cognitive motives - this indicates the average level of formation of the motivational component of the culture of brain work, because there is not so much desire for personal development as the desire to avoid failure and not to meet parents' and teachers' expectations.

The results of the study of the motives of educational activities of pupils of inclusive classes are summarized in table 4.

Table 4

Determining the motives of learning activities of pupils in inclusive classes

\begin{tabular}{|c|c|c|c|c|c|c|c|c|}
\hline \multirow{4}{*}{ Indicators } & \multicolumn{8}{|c|}{ Pupils of inclusive classes ( 37 people) } \\
\hline & \multicolumn{4}{|c|}{ With standard development } & \multicolumn{4}{|c|}{$\begin{array}{l}\text { With special educational needs, } \\
2 \text { classes ( } 9 \text { people) }\end{array}$} \\
\hline & \multicolumn{2}{|c|}{$\begin{array}{c}2 \text { classes } \\
\text { (12 people) }\end{array}$} & \multicolumn{2}{|c|}{$\begin{array}{c}3 \text { classes } \\
(16 \text { people) }\end{array}$} & \multicolumn{2}{|c|}{$\begin{array}{l}2 \text { classes } \\
\text { (6 people) }\end{array}$} & \multicolumn{2}{|c|}{$\begin{array}{l}3 \text { classes } \\
\text { (3 people) }\end{array}$} \\
\hline & Stage & $\begin{array}{c}\text { Stage } \\
2 * *\end{array}$ & Stage & $\underset{2 * *}{\text { Stage }}$ & $\begin{array}{c}\text { Stage } \\
1 *\end{array}$ & $\begin{array}{c}\text { Stage } \\
2 * *\end{array}$ & $\begin{array}{c}\text { Stage } \\
1 *\end{array}$ & $\begin{array}{l}\text { Stage } \\
2 * *\end{array}$ \\
\hline $\begin{array}{l}\text { Harmonious combination } \\
\text { of motives }\end{array}$ & 2 & 4 & 3 & 6 & - & 2 & - & 1 \\
\hline $\begin{array}{l}\text { Domination of cognitive } \\
\text { motives }\end{array}$ & 4 & 6 & 4 & 7 & 2 & 3 & 2 & 2 \\
\hline $\begin{array}{l}\text { Dominance of social } \\
\text { motives }\end{array}$ & 6 & 2 & 9 & 3 & 4 & 1 & 1 & - \\
\hline
\end{tabular}

Generalization and analysis of the results of diagnostics of the level of formation of the culture of brain work of primary schoolchildren before and after the experiment showed positive changes in all components of this phenomenon in all pupils. Students in inclusive classes have different levels of psychophysiological development, but the data shows that the 
indicators of different quality parameters in children with typical and atypical development do not actually differ either before or after the experiment, showing similar positive dynamics (in quantitative terms). Given this, we can conclude:

- firstly, joint inclusive learning of pupils with typical and atypical development has a positive impact on personal, cognitive, emotional and creative development of all children,

- secondly, structural components of such personal phenomenon as the culture of brain work of the pupil are identical in both pupils with typical and atypical development (including vision, hearing, speech, musculoskeletal disorders), and in the course of the purposeful work of the teacher on the development of activity, independence, creativity, motivation of children, these components demonstrate positive dynamics of the entire sample group of students.

\section{Pedagogical conditions for the development of the culture of brain work of primary schoolchildren in inclusive classes}

We have developed a system of exercises that stimulate the development of a culture of brain work of pupils and encourage pupils with atypical development to participate in various types of educational activities - group and pair work, project activities, didactic games, quizzes, joint collective creativity. Let us briefly focus on those types of exercises that develop cognitive and motivational components of the culture of brain work of a primary schoolchild.

For us, one of the indicators of the development of pupils' ability to analyze and synthesize (these skills are the basis for the formation of the foundations of the culture of brain work) was understanding by children of figurative, metaphorical meaning of words. We are convinced that the ability to interpret semantic meanings of words and interpret them in different contexts in early school age and, in particular, with disorders of standard development, is an indicator of flexibility of thinking of the child, the key to successful communication with peers and other members of the society, opens the way to a deep understanding of the language of various arts, stimulates the development of worldview, erudition, the formation of structures of self-awareness. Obviously, many metaphors, especially artistic ones, are difficult to understand for primary schoolchildren. Children's failure to understand metaphors can lead to difficulties in learning and communication. Children with developmental disabilities are more likely to have difficulty encountering the metaphor. These difficulties may be due to various factors specific to each pupil. Identifying these factors becomes an urgent task, as it makes it possible to adjust the existing methods of working on polysemantic words and expand the arsenal of these methods for each of the specific types of developmental disorders, thus contributing to better adaptation of children.

Therefore, we used stimulus material to understand and explain the metaphors found in learning materials for primary school.

To do this, the children who participated in the experiment were asked a question such as: "What does X mean?", where X is one of 14 phrases. The answers of the studied were recorded on a dictaphone and transferred to the protocol word for word at the end. In case of unclear answers, clarifying questions were asked. The main result of the first stage was data on the understanding of a metaphor, but in parallel, answers to questions about literal statements were obtained. These data can be interpreted as solving the problem of identifying the essential features of conventional categories ("fish", "bird", "fruit", etc.).

At the second stage, the recognition of metaphors was diagnosed: the studied was asked questions such as: "The phrases "The sun is an orange" and "An apple is a fruit" are the same or different?". The following sentence pairs were used: 


\section{Metaphor/Without metaphor:}

The sun is an orange. An apple is a fruit.

A river is a snake. A crocodile is an animal.

Without metaphor/Without metaphos:

A pike is a fish. A bee is an insect.

An airplane is a transport. The earth is a planet.

Metaphor/Metaphor:

A helicopter is a beetle. A ballerina is a butterfly.

A lake is a mirror. The moon is a lantern.

The correct answer to recognition question says nothing about the nature of intellectual operations used by the child. Therefore, to identify such a character, the child was asked to explain his answer and for this purpose the question was asked: "Why are they the same/ different?".

Primary school children show good results in the interpretation of metaphors, but it should be noted that their understanding differs from the understanding of metaphors by adults, especially because this understanding remains largely unconscious. Children interpret metaphors correctly, but do not distinguish them among other expressions of language.

One of the most difficult for children of primary and even middle school age understanding type of figurative meaning of the word is metaphorical expressions that are part of proverbs and sayings, set-expressions. This is especially difficult for children with visual and hearing impairments, as well as autism spectrum disorders. The figurative meaning of the proverb is not only generalized in nature, but also always has some educational meaning.

The ability to understand metaphors in children with typical development is related to individual characteristics of their intellectual functions: the higher the level of intellectual development is, the easier the child understands metaphorical expressions. In addition, the ability to understand metaphors is associated with the level of development of visual representations and the ability to establish verbal associations.

Students with hearing impairments often interpret metaphors and idioms literally. Thus, the meaning of the word "painted" in the sentence "Look how it painted the windows", where this is about frost, they interpreted as follows: "The boy coloured on the board", "The girl coloured the house", "The boy coloured a cat". This category of children is characterized by too wide word usage, or vice versa - excessively narrow and specific perception of words.

The system of exercises developed by us can be applied both at the lessons of a native language, and at reading lessons, "I explore the world", in extracurricular activities. The correct perception of polysemantic words, linguistic metaphors (a bump on the forehead, head and tail of a train, cheeks glow, etc.) is facilitated by the use of a counter-image ("incorrect pictures" and "incorrect expressions"). Its effectiveness is explained by visual collision of direct and figurative meaning of the word. The teacher at the lesson draws attention to the fact that objects named by the same word have similarities (determine the basis of transference), i.e. establish in which part of a polysemantic word its meanings meet, intersect, "overlap" with each other.

To do this, pupils compare objects, noticing similarities and differences in color, shape, size and other characteristics, as if transferring the characteristics of one object to another: 1. - What does a sunflower look like? - What do the sun and sunflowers have in common? - We offer a riddle: the Sun is standing on a leg in the garden by the path, but its yellow rays do not give warmth.

2. - Look at the sky. How do you see the clouds? What do they look like? After the pupils' answers, the teacher acquaints with the literary examples of how the masters of the word saw the clouds: white, like milk, clouds approached from the edge of the sky (According 
to M. Kotsiubynskyi). The explanation of many phrases is based on ambiguous words: He has a head on his shoulders - he will do this task or This boy is with the head - he will find the right solution. Why do they say so only about a smart person while everyone has a head? Children answer this question after explaining the meaning of the word "head". With the help of short contexts suggested by the teacher (such as phrases "shake your head", "curly head" or "smart head", "clear head"), pupils find out the literal and figurative meaning of the word "head". Then the teacher focuses their attention on the figurative meaning - "mind, consciousness", which helps to bring pupils to understand the meaning of these phrases.

Exercise "Finish the fairy tale" (collective, frontal work with the class, possible answers in turn, possible at will).

We offer children to finish the text of a fairy tale about a small dandelion, supplementing it with the necessary words in such a way that we have a fairy tale about an adult dandelion. The text can be supplemented with own words or taken from the section "Words to help".

Once in the morning

Dandelion! Where are you? Where did your recognizable: you, it turns out, are already completely

The ball of your head became fog caught on

shaking hat, afraid to lose stems and remained in the grass.

head hide? You are not ! a , as if pieces of there the wind-brawler runs headlong along the meadow; he will now surprise you suddenly. A dandelion shakes its fluffy head left and right, from top to bottom, and laughs: "We'll see: who will win? I am a (an) strong flower, one has to try very hard to tangle my hair!"

Words to help:

Weightless, orange, adult, large, silver, fluffy, grey, strong, flower, large, parachutes, braids, dreamy.

Organized in this way activities in the classroom have a positive effect on the development of creative imagination, logic, thinking and speech of children, stimulates group creativity, communication, facilitates adaptation to learning conditions and forms in pupils of inclusive class tolerant attitude, culture of brain work, activity and independence in achieving learning goals.

\section{Conclusions}

The system of methods and techniques tested by us allowed to define pedagogical conditions which promote development of culture of brain work of primary schoolchildren with special educational needs and with standard development:

- well-thought-out choice of didactic methods by the teacher, techniques and means that will stimulate verbal creativity and group communication (annotated reading, composing fairy tales, riddles, illustrating fairy tales, metaphorical expressions, idioms);

- stimulating group communication in class through the use of such didactic forms as pair and group work, cooperative learning;

- creating a situation of success for each pupil of an inclusive class through the encouragement of creativity, originality and independence;

- observance of the principles of pedagogical optimism, faith in the strength of the child, accessibility and emotionality of educational material, the activity principle of correction of impaired development in the educational process. 
In the course of psychological diagnostics of changes in children's development we noticed that the structural components of such personal phenomenon as the culture of brain work of students are identical in both pupils with typical and atypical development (including visual, hearing, speech, musculoskeletal disorders), and due to persistent work of the teacher on the development of activity, independence, creativity, motivation of pupils, these components demonstrate positive dynamics throughout the sample of pupils.

The study does not cover all aspects of this problem. Techniques of the development of the culture of brain work of children with autism in inclusive environment need further development, search for the strategies to ensure the fullest integration of all categories of pupils in educational process and social life.

\section{References}

Dyachenko, O.M. (1996). Razvitie voobrazheniya doshkolnika [Preschooler's imagination development]. M.: Mezhdunarodnyiy Obrazovatelnyiy i Psihologicheskiy Kolledzh. [in Russian].

Holodnaya, M.A. (2002). Psihologiya intellekta: Paradoksyi issledovaniya [Psychology of intelligence: paradoxes of research]. SPb.: Piter. [in Russian].

Kabanova-Meller, E.N. (1968). Formirovanie priemov umstvennoy deyatelnosti i umstvennoe razvitie uchaschihsya [Formation of methods of mental activity and mental development of the child]. Moscow: Prosveshcheniye. [in Russian].

Leontiev, A.N. (1975). Deyatelnost. Soznanie. Lichnost [Activity. Consciousness. Personality]. Moscow: Politizdat [in Russian].

Shchedrovitskiy, G.P. (1996). Teoriya deyatelnosti $i$ yeyo problemy [Activity theory and its problems]. Moscow: Politizdat [in Russian].

Zubra, A.S. (2006). Kultura umstvennogo truda studenta [The culture of the student's mental work]. Minsk: Dikta. [in Russian].

Tim, Loreman, Joanne, Deppeler, David, Harvey. (2004). Inclusive Education. A practical guide to supporting diversity in the classroom. Routledge. [in English]. 